\title{
Enraizamento de estacas de Psidium guajava L. 'Século XXI' tratadas com ácido indolbutírico veiculado em talco e álcool
}

\author{
Cutting rooting of Psidium guajava L. 'Século XXI' guava treated with indolebutyric acid \\ with talc and alcohol as a vehicle
}

\begin{abstract}
Lilian Yukari Yamamoto ${ }^{\mathrm{I}}$ Rogério de Sá Borges ${ }^{\mathrm{I}}$ Mauren Sorace ${ }^{\mathrm{I}}$ Breno Francovig Rachid ${ }^{\mathrm{I}}$ João Miguel Francisco Ruas ${ }^{\mathrm{I}}$ Osvaldo Sato ${ }^{\mathrm{I}}$ Adriane Marinho de Assis ${ }^{\mathrm{II}}$ Sérgio Ruffo Roberto ${ }^{\mathrm{III}}$
\end{abstract}

\section{RESUMO}

Na produção comercial de Psidium guajava $\mathbf{L}$. (goiabeira), a qualidade das mudas é de fundamental importância, a fim de garantir a homogeneidade, a rápida formação, a alta produtividade e o início precoce da produção, tornando-se imprescindível a utilização da propagação assexuada. O objetivo deste trabalho foi avaliar o enraizamento de estacas de Psidium guajava L. 'Século XXI' tratadas com diferentes concentrações de ácido indolbutírico (AIB) veiculados em talco e álcool. Foram utilizadas estacas herbáceas de 10 $12 \mathrm{~cm}$, submetidas a duas formas de aplicação (solução hidroalcóolica e talco) e três concentrações (0; 1000 e 2000mg $\left.L^{-1}\right)$ de AIB. As estacas foram enraizadas em caixas plásticas contendo casca de arroz carbonizada. O delineamento experimental foi o inteiramente casualizado, com cinco repetições, em um fatorial $2 \times 3$, sendo cinco repetições de 10 estacas. Após 95 dias, foram avaliadas as variáveis: sobrevivência das estacas (\%); retenção foliar (\%); estacas enraizadas (\%); número de raízes por estaca; comprimento de raízes por estaca $(\mathrm{cm})$ e massa seca das raízes por estaca $(\mathrm{g})$. Os melhores resultados para a porcentagem de estacas enraizadas $(28,5 \%)$; número de raízes por estaca $(12,10) e$ comprimento da raiz $(6,79 \mathrm{~cm})$ foram obtidos com a maior concentração de AIB. A partir dos resultados obtidos, concluise que a aplicação de $2000 \mathrm{mg} \mathrm{L}^{-1}$ de AIB proporcionou as melhores características de enraizamento em estacas herbáceas da goiabeira 'Século XXI' e a sua veiculação em talco se mostrou mais eficiente que em álcool.

Palavras-chave: propagação, estaquia, regulador de crescimento, AIB.

\begin{abstract}
In commercial production of Psidium guajava $\mathbf{L}$. (guava) seedlings quality is of paramount importance in order to ensure uniformity, rapid formation, high productivity and early production, making it essential to vegetative propagation. The aim of this research was to evaluate the cutting rooting of Psidium guajava L. 'Século XXI' treated with different concentrations of indolebutyric acid (IBA) with talc and alcohol as a vehicle. Herbaceous cuttings with $10-12 \mathrm{~cm}$ were submitted to two forms of applications (alcoholic talc and alcoholic solution) and three doses $\left(0 ; 1000\right.$ and $\left.2000 \mathrm{mg} \mathrm{L}^{-1}\right)$ of IBA. The cuttings were placed in plastic boxes containing carbonized rice husk. The experimental design was complete randomized, two-way ANOVA (2x3) with five replicates of ten cuttings. After 95 days, the following variables were evaluated: cutting survival rate (\%); foliar retention (\%); rooted cuttings (\%); root number per cutting; root length per cutting and dry root matter per cutting $(\mathrm{g})$. The best results for the percentage of rooting (28.5\%), number of roots per cutting (12.10) and root length $(6.79 \mathrm{~cm})$ were obtained with the highest concentration of IBA. The results showed that the application of $2000 \mathrm{mg} \mathrm{L}^{-1}$ of AIB is the most appropriate to provide the best rooting characteristics of 'Século XXI' guava and the use of talc as an vehicle is more efficient than alcohol.
\end{abstract}

Key words: propagation, rooting, growth regulators, IBA.

\section{INTRODUÇÃO}

Psidium guajava L. (goiabeira), Myrtaceae, é nativa da América tropical, mas muito conhecida pela grande adaptação e produção em diferentes locais do

\footnotetext{
'Programa de Pós-graduação em Agronomia, Centro de Ciências Agrárias (CCA), Universidade Estadual de Londrina (UEL), Londrina, PR, Brasil.

"Programa Nacional de Pós-doutorado, CCA, UEL, Londrina, PR, Brasil.

IIDepartamento de Agronomia, UEL, CP 6001, 86051-990, Londrina, PR, Brasil. E-mail: sroberto@uel.br. Autor para correspondência
} 
mundo (MELETTI, 2000; MANICA et al., 2001). A cultivar Século XXI é destinada à industrialização e ao consumo na forma de fruta fresca, apresentando ciclo precoce, frutos grandes, polpa espessa e róseoavermelhada e poucas e pequenas sementes, prometendo ser uma excelente opção aos produtores por sua qualidade e produtividade (PEREIRA et al., 2003).

No Brasil, os pomares comerciais são encontrados em São Paulo, Pernambuco, Rio de Janeiro e Minas Gerais, sendo a produção destinada ao mercado de frutas frescas e ao processamento industrial (MELETTI, 2000). Nesse sentido, para a produção de goiaba em escala comercial, a qualidade das mudas é fundamental, a fim de garantir a homogeneidade, a rápida formação, a alta produtividade e o início precoce da produção, tornando-se imprescindível a utilização da propagação assexuada (MELETTI, 2000; FRANCO et al., 2008). No Brasil, o processo de propagação em escala comercial é realizado por meio de estacas de ramos herbáceos, ou seja, retiradas de ramos do último fluxo vegetativo que ainda não sofreram processo de lignificação (MANICA et al., 2001).

Para favorecer o enraizamento de estacas herbáceas, a utilização de reguladores de crescimento é uma prática largamente difundida e especialmente em espécies de difícil enraizamento pode viabilizar a produção de mudas por meio da estaquia (FACHINELLO et al., 2005). Entre estes, as auxinas sintéticas são as mais usadas no processo de estaquia, podendo ser citados o ácido indolbutírico (AIB), ácido naftalenoacético (ANA) e ácido indolacético (AIA). Segundo SARZI \& PIVETTA (2005), a superioridade do AIB vem sendo demonstrada para diferentes espécies, em função da menor mobilidade e maior estabilidade química na estaca quando comparado ao AIA. Além disso, o ANA, embora seja semelhante ao AIB, apresenta o inconveniente de ser mais fitotóxico (FACHINELLO et al., 2005).

O efeito benéfico das auxinas exógenas varia entre espécies, cultivares e concentrações (COSTA JÚNIOR et al., 2003; CAMOLESI et al., 2007; FARIA et al., 2007; ZIETEMANN\& ROBERTO, 2007; COLOMBO et al., 2008). A aplicação de auxina na base das estacas pode ser feita por diferentes vias ou veículos de aplicação, destacando-se a líquida e a em pó. Segundo HARTMANN \& KESTER (2002), a aplicação do AIB pela via líquida é, geralmente, mais efetiva que a aplicação em pó, pois apresenta resultados mais uniformes. Entretanto, FACHINELLO et al. (2005) descrevem que a aplicação via pó apresenta a facilidade de preparo e a durabilidade da mistura.
Nesse contexto, experimentos foram realizados com aplicação de auxinas veiculadas em pó e em solução, evidenciando que as respostas são diferentes em função da cada espécie (PAES et al., 2003; BORTOLINI et al., 2008).

O objetivo deste trabalho foi avaliar o enraizamento de estacas herbáceas de Psidium guajava L. 'Século XXI' tratadas com diferentes concentrações de ácido indolbutírico veiculado em talco e álcool.

\section{MATERIAL E MÉTODOS}

O experimento foi realizado no período de abril a julho de 2009, no Setor de Fruticultura do Centro de Ciências Agrárias da Universidade Estadual de Londrina (UEL), Paraná (PR), localizada a 566m de altitude, $23^{\circ} 23$ de Latitude Sul e $51^{\circ} 11$ de Longitude Oeste. Foram utilizadas estacas herbáceas de 10-12cm, retiradas da parte mediana dos ramos de plantas matrizes da goiabeira 'Século XXI' com oito anos, pertencentes à coleção da Fazenda Escola da Universidade Estadual de Londrina.

Antes de efetuar a coleta das estacas, foi preparada a solução hidroalcóolica do AIB, sendo pesados $0,1 \mathrm{~g}$ de AIB em balança semianalítica e dissolvidos em $50 \mathrm{~mL}$ de álcool, em um becker, com auxílio de agitador eletromagnético. Após totalmente dissolvido o AIB, completou-se o volume para $100 \mathrm{~mL}$, com água destilada, obtendo-se então a concentração de $1000 \mathrm{mg} \mathrm{L}^{-1}$ de AIB. Para o preparo do AIB em talco, $0,1 \mathrm{~g}$ de AIB foi misturado em talco industrial até completar 100g. Para uma melhor homogeneização, acrescentou-se álcool em quantidade suficiente para formar uma pasta, sendo em seguida transferido para estufa a $40^{\circ} \mathrm{C}$, onde permaneceu até a completa evaporação do solvente.

O preparo das estacas incluiu um corte em bisel logo abaixo de um nó, com a eliminação das folhas da parte basal, deixando-se um par de folhas na parte superior. Durante o preparo, as estacas foram dispostas em um recipiente com água para evitar a desidratação. Após o preparo das estacas, o AIB foi aplicado por meio de imersão rápida (10 segundos).

Em seguida, estas foram colocadas em caixas plásticas $(44 \times 30 \times 7 \mathrm{~cm})$ para enraizamento, contendo o substrato casca de arroz carbonizada, em câmara de nebulização, com regime intermitente controlado por temporizador e válvula solenóide. A válvula foi programada para nebulizar durante 10 segundos, a cada três minutos. O bico nebulizador empregado (Modelo Mist DanSprinklers, Israel) apresentou vazão de $35 \mathrm{~L} \mathrm{hora}^{-1}$. A câmara de 
nebulização foi inserida em estufa com cobertura de filme de polietileno transparente e sombrite $30 \%$. Para o controle de doenças fúngicas, as estacas foram tratadas semanalmente com fungicidas à base de tebuconazol. Foi realizada, semanalmente, adubação foliar com fertilizante Biofert Plus ${ }^{\circledR}(8-9-9+$ micro) na proporção $5 \mathrm{~mL} \mathrm{~L}^{-1}$. Durante a condução do experimento, as médias das temperaturas (máximas e mínimas) no interior da estufa foram de 27,7 e $13,2^{\circ} \mathrm{C}$, respectivamente.

Após 95 dias da instalação do experimento, foram avaliadas: sobrevivência das estacas (\% de estacas vivas); retenção foliar (\% de estacas que não perderam as folhas); estacas enraizadas (\% que emitiram pelo menos uma raiz); número de raízes por estaca; comprimento das raízes por estaca $(\mathrm{cm})$ e massa seca das raízes por estaca (g). A massa seca das raízes foi obtida por meio de secagem em estufa com circulação forçada de ar a $78^{\circ} \mathrm{C}$, por $48 \mathrm{~h}$ (CYRILLO et al., 1999).

O delineamento experimental foi inteiramente casualizado, com cinco repetições de 10 estacas em um fatorial 2x3, sendo duas formas de aplicação (talco e álcool) e três concentrações de AIB (0, 1000 e 2000mg $\mathrm{L}^{-1}$ ). Os dados foram submetidos à análise de variância, e as médias foram comparadas pelo teste de Tukey, a 5\% de probabilidade. Efetuou-se a transformação de dados arco seno $\sqrt{\mathrm{x} / 100}$ para as variáveis oriundas de porcentagem e para as variáveis oriundas de contagem efetuou-se a transformação $\sqrt{\mathrm{x}+1}$.

\section{RESULTADOS E DISCUSSÃO}

Com relação à porcentagem de sobrevivência das estacas, verificou-se que a interação entre as concentrações de AIB e as formas de aplicação foi significativa (Tabela 1). Para a concentração de 2000 $\mathrm{mg} \mathrm{L}^{-1}$, a aplicação do regulador de crescimento em solução hidroalcóolica resultou em menor percentual de sobrevivência das estacas (62,5\%), enquanto que na aplicação em talco 94\% das estacas sobreviveram. Tal resultado pode estar relacionado a uma possível toxidez provocada pela maior absorção de AIB em solução mais concentrada. Nas demais médias, a interação dos fatores não provocou reduções expressivas na sobrevivência, mostrando que concentrações menores de AIB em álcool e todas as concentrações de AIB veiculado em talco podem ser usadas sem que sejam observados índices elevados de mortalidade. Entretanto, FRANZON et al. (2004) verificaram que as diferentes concentrações de AIB testadas (0, 2000, 4000 ou $\left.8000 \mathrm{mg} \mathrm{L}^{-1}\right)$ não influenciaram a sobrevivência das estacas de goiabeira-serrana (Acca sellowiana Berg).

Vale ressaltar que, segundo FACHINELLO et al. (2005), a exposição por um tempo mais prolongado à solução concentrada em álcool e a utilização de concentrações muito elevadas podem ocasionar efeitos fitotóxicos, como a inibição do desenvolvimento das gemas, o amarelecimento e a queda de folhas e até mesmo a morte das estacas. Além disso, o uso de AIB veiculado em talco, mesmo em concentrações maiores, é mais seguro por não provocar morte de estacas, além de possibilitar a execução do serviço com mais praticidade e menor custo.

Quanto à retenção foliar, não houve diferenças significativas entre as concentrações e as diferentes formas de aplicação (Tabela 1). No entanto,

Tabela 1 - Sobrevivência das estacas (\%) e retenção foliar (\%) de goiabeira (Psidium guajava L. 'Século XXI'), submetidas a diferentes concentrações de AIB veiculados em talco e em álcool. Londrina, PR, 2009.

\begin{tabular}{|c|c|c|c|c|}
\hline & \multirow{2}{*}{ Concentrações de AIB (mg L ${ }^{-1}$ ) } & -------Form & ação------ & \multirow{2}{*}{ Média } \\
\hline & & Álcool & Talco & \\
\hline & 0 & 96,0 Аa* & 88,0 Аа & 92,0 \\
\hline \multirow[t]{2}{*}{ Sobrevivência das estacas (\%) } & 1000 & $84,0 \mathrm{Aa}$ & $92,0 \mathrm{Aa}$ & 88,0 \\
\hline & 2000 & $62,5 \mathrm{Bb}$ & $94,0 \mathrm{Aa}$ & 78,0 \\
\hline Média & & 82,4 & 91,3 & \\
\hline CV(\%) & & \multicolumn{2}{|c|}{15,39} & \\
\hline \multirow{3}{*}{ Retenção foliar (\%) } & 0 & $18,0 \mathrm{~ns}$ & 20,0 & 19,0 \\
\hline & 1000 & 10,0 & 14,0 & 12,0 \\
\hline & 2000 & 27,5 & 22,0 & 24.8 \\
\hline Média & & 18,5 & 18,7 & \\
\hline CV(\%) & \multicolumn{3}{|c|}{44,94} & \\
\hline
\end{tabular}

*Médias não seguidas por letras iguais maiúsculas nas linhas e minúsculas nas colunas diferem entre si pelo teste de Tukey $(P<0,05)$. ns: não significativo. 
as médias estiveram próximas de $20 \%$, evidenciando a baixa retenção foliar verificada neste experimento.

Em experimento com AIB e sacarose no enraizamento de estacas de Psidium guajava $\mathbf{L}$. 'Paluma', VALE et al. (2008) observaram que concentrações maiores provocaram maior queda de folhas, demonstrando que a presença das folhas não teve influência sobre o enraizamento e que não houve a necessidade da permanência das folhas nas estacas tratadas com $300 \mathrm{mg} \mathrm{L}^{-1}$ de AIB. No entanto, ZIETEMANN \& ROBERTO (2007) não observaram diferenças nas concentrações 500; 1000; 1500 e 2000mg $\mathrm{L}^{-1}$ de AIB para a sobrevivência e retenção foliar das estacas de Psidium guajava L. 'Paluma' e 'Século XXI'. Da mesma forma, COLOMBO et al. (2008) concluíram que não houve diferenças em relação a essas variáveis em estacas de Psidium guajava L. seleção 8501-1, nas concentrações 1000; 2000 e 3000mg L-1 de AIB.

Na avaliação do percentual de enraizamento, não foi verificada interação significativa entre concentrações de AIB e as formas de aplicação (Tabela 2). Contudo, foram verificadas diferenças entre as médias dos tratamentos com as diferentes concentrações, sendo a melhor média obtida com 2000mg $\mathrm{L}^{-1}$, independente da forma de aplicação, mostrando a efetividade do regulador de crescimento no enraizamento. Mesmo que os percentuais tenham sido maiores que os obtidos com as demais concentrações, podem ser considerados baixos (28,5\%), se comparados aos obtidos em outros trabalhos com diferentes cultivares de Psidium guajava L., como 41,0\% (ZIETEMANN \& ROBERTO, 2007); entre 71,09 e 89,71\% (COSTAJÚNIOR et al., 2003) e 60\% (VALE et al., 2008).

Os baixos índices de enraizamento podem ter sido influenciados pela temperatura ambiente, uma vez que, durante a condução do experimento, foram observadas temperaturas abaixo de $24^{\circ} \mathrm{C}$, valor considerado ideal para estimular a divisão celular na área de enraizamento (HANSEN, 1989). Porcentagens reduzidas de enraizamento também foram atribuídas a períodos de temperaturas baixas em trabalhos realizados por COLOMBO et al. (2008), com estacas de Psidium guajava $\mathrm{L}$.

Quanto ao número de raízes por estaca e comprimento das raízes, não foi verificada interação significativa entre as concentrações de AIB e as formas de aplicação (Tabela 2). Verificaram-se diferenças

Tabela 2 - Estacas enraizadas (\%), número de raízes por estaca, comprimento da raiz e massa seca de raízes por estaca (g) de goiabeira (Psidium guajava L. 'Século XXI'), submetidas a diferentes concentrações de AIB veiculados em talco e em álcool. Londrina, PR, 2009.

\begin{tabular}{|c|c|c|c|c|}
\hline & \multirow{2}{*}{ Concentrações de AIB (mg L ${ }^{-1}$ ) } & \multicolumn{2}{|c|}{------Formas de Aplicação------ } & \multirow{2}{*}{ Média } \\
\hline & & Álcool & Talco & \\
\hline & 0 & $0,0 \mathrm{~ns}$ & 6,0 & $3,0 b^{*}$ \\
\hline \multirow{2}{*}{ Estacas enraizadas (\%) } & 1000 & 2,0 & 6,0 & $4,0 \mathrm{~b}$ \\
\hline & 2000 & 35,0 & 22,0 & 28,5 a \\
\hline Média & & 12,3 & 11,3 & \\
\hline CV(\%) & & \multicolumn{2}{|c|}{66,78} & \\
\hline \multirow{3}{*}{ Número de raízes por estaca } & 0 & $0,00 \mathrm{~ns}$ & 0,60 & $0,30 \mathrm{~b}$ \\
\hline & 1000 & 0,20 & 2,60 & $1,40 \mathrm{~b}$ \\
\hline & 2000 & 17,00 & 7,20 & $12,10 \mathrm{a}$ \\
\hline Média & & 5,73 & 3,47 & \\
\hline $\mathrm{CV}(\%)$ & & \multicolumn{2}{|c|}{53,79} & \\
\hline \multirow{3}{*}{ Comprimento da raiz (cm) } & 0 & $0,00 \mathrm{~ns}$ & 1,82 & 0,91 b \\
\hline & 1000 & 0,20 & 2,89 & $1,55 \mathrm{~b}$ \\
\hline & 2000 & 7,03 & 6,54 & 6,79 a \\
\hline Média & & 2,41 B & 3,75 A & \\
\hline CV(\%) & & \multicolumn{2}{|c|}{73,06} & \\
\hline \multirow{3}{*}{ Massa seca de raízes por estaca (g) } & 0 & $0,000 \mathrm{Ab}$ & $0,030 \mathrm{Ab}$ & 0,02 \\
\hline & 1000 & $0,002 \mathrm{Ab}$ & $0,032 \mathrm{Ab}$ & 0,02 \\
\hline & 2000 & 0,726 Аа & 0,321 Ba & 0,52 \\
\hline Média & & 0,24 & 0,13 & \\
\hline CV(\%) & \multicolumn{3}{|c|}{110,66} & \\
\hline
\end{tabular}

*Médias não seguidas por letras iguais maiúsculas nas linhas e minúsculas nas colunas diferem entre si pelo teste de Tukey $(P<0,05)$. ns: não significativo. 
significativas entre as médias das diferentes concentrações de AIB. Nos dois casos, as melhores médias foram obtidas com a concentração $2000 \mathrm{mg} \mathrm{L}^{-1}$, demonstrando que a aplicação de AIB nessa concentração não só aumentou o percentual de enraizamento, como também o número e o comprimento das raízes. No entanto, quanto à forma de aplicação, as médias obtidas, com AIB veiculado em talco, foram significativamente superiores para a variável comprimento das raízes. Segundo ZIETEMANN \& ROBERTO (2007), a emissão de raízes em maior número e comprimento é fundamental quando o objetivo é a produção de mudas em escala comercial, visto que esses fatores são fundamentais na constituição dos pomares. Além disso, o sistema radicular bem formado aumenta a área de solo a ser explorada, favorecendo a absorção de nutrientes e água, o que proporciona um melhor desenvolvimento da muda quando levada a campo (FRACARO \& PEREIRA, 2004; CARVALHO JUNIOR, 2009).

Respostas positivas ao enraizamento de estacas de Psidium guajava L. à aplicação de AIB também foram obtidas por COSTA JÚNIOR et al. (2003), ZIETEMANN \& ROBERTO (2007) e VALE et al. (2008) e, de acordo com FACHINELLO et al. (2005), o teor adequado de auxina exógena para o estímulo do enraizamento depende da concentração existente no tecido. Entretanto, o estímulo ao enraizamento se dá até uma determinada concentração, diferindo para cada espécie, a partir da qual o efeito passa a ser inibitório (ALVARENGA \& CARVALHO, 1983).

Outro fator que pode interferir no enraizamento das estacas refere-se à forma de tratamento destas, que é variável em função do veículo utilizado. Assim, para veículos sólidos, em que o produto fica aderido à base da estaca, o período de exposição é mais prolongado, em comparação com veículos líquidos (CUQUEL \& MINAMI, 1994).

Com relação à massa seca, a maior concentração, tanto em solução, como em talco, conferiu as maiores médias; porém, estas diferiram entre si, sendo o melhor resultado obtido na solução hidroalcoólica (Tabela 2). Esses resultados estão de acordo com ZIETEMANN \& ROBERTO (2007), que obtiveram maior massa seca de raízes de estacas de Psidium guajava L. 'Século XXI' com 1000, 1500 e 2000 $\mathrm{mg} \mathrm{L}^{-1}$ de AIB e para a cultivar Paluma, os melhores resultados foram obtidos nas concentrações de 1500 e 2000 $\mathrm{mg} \mathrm{L}^{-1}$ de AIB. PEREIRA et al. (1991), testando o AIB no enraizamento de estacas de goiabeira, constataram maior número e peso de raízes em estacas tratadas, demonstrando a eficiência da aplicação do regulador e, de acordo com TAVARES et al. (1995), o maior número, o comprimento e a massa seca de raízes resultarão em melhor padronização do desenvolvimento das raízes e da qualidade das mudas formadas.

Com base nos resultados, pôde-se observar que o enraizamento de estacas da Psidium guajava $\mathbf{L}$. 'Século XXI' pode ser obtido com sucesso mediante o uso de AIB, que, quando veiculado em talco, além de propiciar resultados satisfatórios ao enraizamento das estacas, também proporciona menor risco de fitotoxidez às estacas, maior praticidade e menor custo na aplicação. Além disso, na produção comercial de mudas de goiabeira em larga escala, o uso do AIB veiculado em talco permite um melhor controle de sua aplicação, sendo possível verificar por amostragem se as estacas foram devidamente tratadas com o regulador.

\section{CONCLUSÃO}

A aplicação de 2000mg $\mathrm{L}^{-1}$ de AIB proporciona as melhores características quanto à porcentagem de enraizamento, ao número, ao comprimento e à massa seca de raízes em estacas herbáceas da Psidium guajava L. 'Século XXI’ e a sua veiculação em talco é mais eficiente que em álcool.

\section{AGRADECIMENTOS}

À Coordenação de Aperfeiçoamento de Pessoal de Nível Superior (CAPES), pela concessão das bolsas.

\section{REFERÊNCIAS}

ALVARENGA, L.R.; CARVALHO, V.D. Uso de substâncias promotoras de enraizamento de estacas de frutíferas. Informe Agropecuário, Belo Horizonte, v.9, n.101, p.47-55, 1983.

BORTOLINI, M.F. et al. Tibouchina sellowiana (Cham.) Cogn.: enraizamento, anatomia e análises bioquímicas nas quatro estações do ano. Ciência Florestal, Santa Maria, v.18, n.2, p.159-171, 2008.

CAMOLESI, M.R. et al. Enraizamento de estacas semilenhosas de pessegueiro “Okinawa” sob efeito de lesão e ácido indolbutírico. Ciência Rural, Santa Maria, v.37, n.6, p.18051808, nov./dez. 2007. Disponível em: <http://www.scielo.br/ s c i e l o.ph p ? s c ri pt = s c i_art text \& pid = S 0103 84782007000600048\&lng=pt\&nrm=iso>. Acesso em: 08 jul. 2009. doi: 10.1590/S0103-84782007000600048.

CARVALHO JUNIOR, W.G.O. et al. Comprimento da estaca no desenvolvimento de mudas de alecrim-pimenta. Ciência Rural, Santa Maria, v.39, n.7, p.2199-2202, 2009. Disponível em: $<$ http://www.scielo.br/scielo.php?script=sci_arttext\&pid=S010384782009000700038\&lng=pt\&nrm=iso $>$. Acesso em: 20 jan. 2010. doi: 10.1590/S0103-84782009005000152.

CYRILLO, F.L.L. et al. Multiplicação de porta-enxertos de videira por meio de estacas semilenhosas, em dois substratos, conduzidos em câmara de nebulização. Revista Brasileira de Fruticultura, Jaboticabal, v.21, n.3, p.266-268, 1999. 
COLOMBO, L.A. et al. Enraizamento de estacas herbáceas da seleção 8501-1 de goiabeira submetidas a lesão na base e a concentrações de AIB. Semina: Ciências Agrárias, Londrina, v.29, n.3, p.539-546, 2008.

COSTA JÚNIOR, W.H. et al. Estiolamento da planta matriz e uso de ácido indolbutírico no enraizamento de estacas de goiabeiras. Revista Brasileira de Fruticultura, Jaboticabal, v.25, n.2, p.301-304, 2003. Disponível em: <http:// www.scielo.br/scielo.php?script=sci_arttext\&pid=S010029452003000200030\&lng=pt\&nrm=iso>. Acesso em: 20 jul. 2009. doi: 10.1590/S0100-29452003000200030.

CUQUEL, F.L.; MINAMI, K. Enraizamento de estacas de crisântemo (Dendranthema morifolium (Ramat.) Tzvelev) tratadas com ácido indolbutírico veiculado em talco. Scientia Agricola, Piracicaba, v.51, n.1, p.28-35, 1994. Disponível em: $<$ http://www.scielo.br/scielo.php?script=sci_arttext\&pid=S010390161994000100005\&lng=pt\&nrm=iso $>$. Acesso em: 12. jun. 2009. doi: 10.1590/S0103-90161994000100005.

FACHINELLO, J.C. et al. Propagação de plantas frutíferas. Brasília: Embrapa Informações Tecnológicas, 2005. 221p.

FARIA, A.P. et al. Enraizamento de estacas semilenhosas do porta-enxerto de videira 'IAC 572-Jales' tratadas com diferentes concentrações de ácido indolbutírico. Semina: Ciências Agrárias, Londrina, v.28, n.3, p.393-398, 2007.

FRACARO, A.A.; PEREIRA, F.M. Distribuição do sistema radicular da goiabeira 'Rica' produzida a partir de estaquia herbácea. Revista Brasileira de Fruticultura, Jaboticabal, v.26, n.1, p.183-185, 2004. Disponível em: <http:// www.scielo.br/scielo.php?script $=$ sci_arttext \&pid $=$ S010029452004000100049\&lng=pt\&nrm=iso>. Acesso em: 24 jun. 2009. doi: 10.1590/S0100-29452004000100049.

FRANCO, C.F. et al. Marcha de absorção dos micronutrientes para mudas de goiabeiras cultivares Paluma e Século XXI. Bragantia, Campinas, v.67, n.1, p.83-90, 2008. Disponível em: $<$ http://www.scielo.br/scielo.php?script=sci_arttext\&pid=S000687052008000100010\&lng=pt\&nrm=iso>. Acesso em: 23 jun. 2010. doi: 10.1590/S0006-87052008000100010.

FRANZON, R. et al. Efeito do AIB e de diferentes tipos de estaca na propagação vegetativa da goiabeira-serrana (Acca sellowiana Berg). Revista Brasileira de Agrociência, Pelotas, v.10, n. 4, p. 515-518, 2004.

HANSEN, J. Influence of position and temperature during rooting of adventitious root formation and axilary bud break of Stephanotis floribunda. Scientia Horticulturae, Amsterdam, v.40, n.4, p.345-354, 1989.
HARTMANN, H.T.; KESTER, D.E. Plant propagation: principles and practices. 7.ed. New Jersey: Prentice-Hall, 2002. 880p.

MANICA, I. et al. Goiaba: do plantio ao consumidor: tecnologia de produção, pós-colheita, comercialização. Porto Alegre: Cinco Continentes, 2001. 124p.

MELETTI, L.M.M. Propagação de frutíferas. Guaíba: Agropecuária, 2000. 239p.

PAES, E.G.B. et al. Enraizamento de estacas de kiwizeiro (Actinidia deliciosa Lang et Ferguson cv. Bruno) nas quatro estações do ano. Scientia Agraria, Curitiba, v.4, n.1-2, p.6976, 2003

PEREIRA, F.M. et al. Século XXI: nova cultivar de goiabeira de dupla finalidade. Revista Brasileira de Fruticultura, Jaboticabal, v.25, n.3, p.498-500, dez. 2003. Disponível em: $<$ http://www.scielo.br/scielo.php?script=sci_arttext\&pid=S010029452003000300034\&lng=pt\&nrm=iso $>$. Acesso em: 23 jun. 2009. doi: 10.1590/S0100-29452003000300034.

PEREIRA, F.M. et al. Efeito do ácido indolbutírico no enraizamento de estacas herbáceas de goiabeira (Psidium guajava L.) das cultivares "Rica” e "Paluma", em câmara de nebulização. Científica, São Paulo, v.19, n.2, p.199-206, 1991.

SARZI, I.; PIVETTA, K.F.L. Efeito das estações do ano e do ácido indolbutírico no enraizamento de estacas de variedades de minirroseira (Rosa spp.). Científica, Jaboticabal, v.332, n.1, p.62-68, 2005.

TAVARES, M.S.W. et al. Efeitos do ácido indolbutírico e da época de coleta no enraizamento de estacas de goiabeira (Psidium guajava L.). Scientia agrícola, Piracicaba, v.52, n.2, p.310-317, 1995. Disponível em: <http://www.scielo.br/scielo.php?script=sci_arttext\&pid=S010390161995000200018\&lng=pt\&nrm=iso>. Acesso em: 20 jul. 2009. doi: 10.1590/S0103-90161995000200018.

ZIETEMANN, C.; ROBERTO, S.R. Efeito de diferentes substratos e épocas de coleta no enraizamento de estacas herbáceas de goiabeira, cvs. paluma e século XXI. Revista Brasileira de Fruticultura, Jaboticabal, v.29, n.1, p.31-36, 2007. Disponível em: <http:// www.scielo.br/scielo.php?script=sci_arttext\&pid=S010029452007000100009\&lng=pt\&nrm=iso>. Acesso em: 7 jul. 2009. doi: 10.1590/S0100-29452007000100009.

VALE, M.R. do et al. Ácido indolbutírico e sacarose no enraizamento de estacas de goiabeira cultivar Paluma. Caatinga, Mossoró, v.21, n.3, p.69-74, 2008. 